\title{
Clinical utility of pharmacogenomics in the management of hepatitis $C$
}

This article was published in the following Dove Press journal:

Pharmacogenomics and Personalized Medicine

20 October 2014

Number of times this article has been viewed

Julieta Trinks ${ }^{1,2}$

María Laura Hulaniuk'

María Ana Redal ${ }^{1,3}$

Diego Flichman ${ }^{2,4}$

'Instituto de Ciencias Básicas y Medicina Experimental, Hospital Italiano de Buenos Aires, ${ }^{2}$ National Scientific and Technical Research Council, ${ }^{3}$ Instituto Universitario del Hospital Italiano de Buenos Aires, ${ }^{4}$ Cátedra de Virología, Facultad de Farmacia y Bioquímica, Universidad de Buenos Aires, Buenos Aires, Argentina

Correspondence: Julieta Trinks Instituto de Ciencias Básicas y Medicina Experimental, Hospital Italiano de Buenos Aires, Potosí 4240, CII99ACL, Buenos Aires, Argentina Tel +54 II 49590200 ext 5453 Fax +54 II 49590200 ext 4I55 Email julieta.trinks@hospitalitaliano.org.ar
Abstract: Hepatitis C virus (HCV) was identified for the first time more than 20 years ago. Since then, several studies have highlighted the complicated aspects of this viral infection in relation to its worldwide prevalence, its clinical presentation, and its therapeutic response. Recently, two landmark scientific breakthroughs have moved us closer to the successful eradication of chronic HCV infection. First, response rates in treatment-naïve patients and in prior non-responders to pegylated-interferon- $\alpha$ and ribavirin therapy are increasing as a direct consequence of the development of direct-acting antiviral drugs. Secondly, the discovery of single-nucleotide polymorphisms near the interleukin $28 \mathrm{~B}$ gene significantly related to spontaneous and treatment-induced $\mathrm{HCV}$ clearance represents a milestone in the $\mathrm{HCV}$ therapeutic landscape. The implementation of this pharmacogenomics finding as a routine test for $\mathrm{HCV}$-infected patients has enhanced our understanding of viral pathogenesis, has encouraged the design of ground-breaking antiviral treatment regimens, and has become useful for pretreatment decision making. Nowadays, interleukin 28B genotyping is considered to be a key diagnostic tool for the management of HCV-infected patients and will maintain its significance for new combination treatment schemes using direct-acting antiviral agents and even in interferon-free regimens. Such pharmacogenomics insights represent a challenge to clinicians, researchers, and health administrators to transform this information into knowledge with the aim of elaborating safer and more effective therapeutic strategies specifically designed for each patient. In conclusion, the individualization of treatment regimens for patients with hepatitis $\mathrm{C}$, that may lead to a universal cure in future years, is becoming a reality due to recent developments in biomarker and genomic medicine. In light of these advances, we review the scientific evidence and clinical implications of recent findings related to host genetic factors in the management of HCV infection.

Keywords: hepatitis C virus, pharmacogenomics, interleukin $28 \mathrm{~B}$, inosine triphosphatase

\section{Introduction}

Modern therapeutics requires adequate drug prescription, which implies the selection of the correct drug, dose, and duration of administration. However, it has been reported that, in approximately $30 \%-60 \%$ of patients, drugs that are correctly prescribed cannot provide the desired outcome. ${ }^{1}$

The consequence of a series of pharmacokinetic processes, which take place at dissimilar levels in different subjects, determines the pharmacological effects of the majority of drugs, the host genetic background being involved in this variability. In fact, the existence of genetic variants could alter the structure, function, and expression of most of the enzymes that are engaged in drug transport and metabolism or the particular drug receptors, so the phenotypic behavior of the patient can be predicted 
by genotyping, which sets the basis for pharmacogenomics studies. $^{2}$

Modifications of a single base in the nucleotide sequence, known as single-nucleotide polymorphisms (SNPs), are the most common variants and targets of pharmacogenetic tests. Although there are hundreds of thousands of SNPs, the kinetics or dynamics of drugs seem to be influenced by only a small minority of them. ${ }^{3}$

Recently, a revolutionary era in scientific research has been established after the culmination of the Human Genome Project, and a new approach, ie, the genome-wide association study, represents its main success. Genetic factors strongly related to disease susceptibility and drug response are finally being identified as a result of the use of this modern high-throughput genotyping technology, which analyzes 300,000-900,000 SNPs in each sample. ${ }^{4}$

Following the rise of the genomic era, the clinical and therapeutic management of many diseases, including even those of infectious origin, was expected to evolve. Nonetheless, up to the present, there are scarce examples of the use of such new data in routine clinical practice, hepatitis $\mathrm{C}$ virus $(\mathrm{HCV})$ being one of the most encouraging cases.

The identification of key molecular biomarkers for $\mathrm{HCV}$ has brought understanding of the dissimilarities observed in disease progression and treatment response, helping us to comprehend the natural history of $\mathrm{HCV}$, estimate the burden of infection, and develop preventive measures. $^{5-9}$

These findings impact the prognosis and treatment of HCV infection. Further, the ability to identify patients with an unfavorable allele, in whom the response to treatment would be very poor, would spare some patients the side effects of standard treatment that is unlikely to be beneficial, thereby making them candidates for alternative emerging therapies.

Such pharmacogenomics insights represent a challenge for clinicians, researchers, and health administrators to transform this information into knowledge with the aim of elaborating safer and more effective therapeutic strategies specifically designed for each patient.

Similarly to what is observed in other areas of modern therapeutics, pharmacogenomics tests are acquiring a position in the treatment of infectious diseases. However, these analyses do not elucidate all of the variability in treatment response. Therefore, as the goal is to enhance the patient's therapeutic experience, genetic and non-genetic information, such as sex, age, viral load, genotype, drug interactions, and clinical observations, must be merged in this modern paradigm of individualized HCV therapy in order to decide the most suitable treatment for a given patient. ${ }^{10,11}$

In this review, we summarize the scientific evidence and clinical implications of recent findings related to host genetic factors in the management of HCV infection.

\section{Genetics of IL28B: impact and effect on treatment response in HCV patients}

$\mathrm{HCV}$ was identified for the first time more than 20 years ago. ${ }^{12}$ Since then, several studies have highlighted the complicated aspects of this viral infection in relation to its worldwide prevalence, its clinical presentation, and its response to therapy. ${ }^{13-17}$

With approximately $3 \%$ of the world population, that is, more than 170 million people, now infected, HCV is considered to be a major health problem. The clinical manifestations are varied, ranging from an asymptomatic self-limiting infection to liver cirrhosis and hepatocellular carcinoma, which are the main indications for liver transplantation in developed countries. As a consequence, the socioeconomic implications of the infection are enormous, and the burden of the disease is expected to intensify worldwide as the liver damage progresses in patients who acquired HCV many years earlier. ${ }^{13}$

In spite of the high costs and substantial toxicity of pegylated-interferon- $\alpha$ and ribavirin (PEG-IFN- $\alpha /$ RBV) combination therapy, a sustained virological response (SVR), that is, undetectable HCV RNA in serum 6 months after treatment completion, can be obtained by less than $50 \%$ of patients infected with the most prevalent HCV genotype. ${ }^{14}$ Despite the fact that direct-acting antiviral agents are expected to increase the response rate markedly, these new drugs must currently be administered in combination with PEG-IFN- $\alpha$ / RBV to help suppress viral breakthrough. ${ }^{15}$

In addition, the achievement of SVR depends on several viral (eg, genotypes, viral load, mutations) and host (eg, age, sex, degree of liver fibrosis, alcohol consumption) factors. However, despite these influencing characteristics, a large proportion of the variability as well as the existence of ethnic disparities in treatment response cannot be completely explained. Therefore, it had been strongly suggested that host genetic risk factors might be also involved in the response of $\mathrm{HCV}$ to treatment. ${ }^{16,17}$

A few years ago, through the use of genome-wide association studies, four independent research groups analyzed the role of variation in host genetic markers in response to treatment with PEG-IFN- $\alpha /$ RBV for patients chronically 
infected with HCV genotype $1 b^{5-8}$ Despite the fact that patients from different ethnic origins (European, African American, Hispanic, Australian, and Japanese) were included in these studies, the definitive conclusion in all cases was that polymorphisms in or near the interleukin (IL) 28B gene, also known as interferon (IFN) lambda 3 (IFN- $\lambda 3$ or IFNL3), on chromosome 19 significantly affect the response to $\mathrm{HCV}$ therapy. These SNPs are in high-linkage disequilibrium with each other, meaning that their variants are strongly related, so offer very similar genetic associations.

In fact, a response to PEG-IFN- $\alpha / \mathrm{RBV}$ combination therapy in patients infected with HCV genotype $1 \mathrm{~b}$ was significantly $\left(P<7.1 \times 10^{-08}\right)$ more likely to occur in those with a particular genotype in the $I L 28 B$ locus (rs 12979860 CC or rs $8099917 \mathrm{TT}$ ) than in patients with other $I L 28 B$ variants. ${ }^{5-8}$ Such individuals were also more likely to spontaneously clear acute $\mathrm{HCV}$ infection without treatment. ${ }^{9}$

As epidemiological studies have also demonstrated, these ground-breaking data confirmed that ethnicity is closely related to the response to treatment for $\mathrm{HCV}$. The prevalence of these polymorphisms differs between ethnic groups, ${ }^{9,18}$ which could explain much of the recognized ethnic discrepancy in the frequency of SVR rates; for example, the treatment response rates in European (53\%-85\%), Asian (90\%), and African-American (23\%-55\%) patients might be partly elucidated by the finding that the C allele of SNP rs 12979860 is less prevalent among individuals of African descent than in those of European and Asian ancestry. ${ }^{7,9}$

The correlation between $I L 28 B$ polymorphisms and therapeutic response was confirmed by various research groups and across different HCV genotypes, ${ }^{19-22}$ as well as in individuals coinfected with human immunodeficiency virus. ${ }^{8,23}$

Although on-treatment predictors, such as rapid virological response, defined as the lack of detection of HCV RNA in serum at the fourth week of treatment, are more precisely associated with therapeutic outcome, ${ }^{24,25}$ the $I L 28 B$ SNP is considered the strongest pretreatment predictor of response. ${ }^{26}$ This is explained by the fact that patients with the favorable IL28B genotype tend to have a higher initial baseline viral load, appear to eliminate the virus more efficiently at each time point of treatment, and, therefore, are more prone to achieving a rapid virological response. $724,26-32$

Recurrent $\mathrm{HCV}$ infection after liver transplantation is frequent and demands post-transplant antiviral treatment. ${ }^{33-35}$ In these patients, $I L 28 B$ genotyping could also be beneficial to predict and control the risk of reinfection. It has been reported that a severe recurrence of $\mathrm{HCV}$ infection is more frequent among recipients with the unfavorable alleles, and that $I L 28 B$ variants in donors and recipients are independently related to the post-transplant therapeutic response, indicating that donors with the favorable IL28B genotype might be more appropriate for $\mathrm{HCV}$-infected patients. ${ }^{34}$

\section{IL28B gene family}

The cytokines IL29, IL28A, and IL28B (also known as IFN- $\lambda 1$, IFN- $\lambda 2$, and IFN- $\lambda 3$, respectively) are the three members of the type III IFN- $\lambda$ family. In agreement with the knowledge that these cytokines act primarily as IFNs and not as ILs, the Human Genome Organization Gene Nomenclature Committee has changed the official symbols to IFNL1, IFNL2, and IFNL3, respectively. ${ }^{36}$ The three IFN- $\lambda$ s, expressed at low levels by a wide array of human tissues, can be activated by viral infection and stimulate both innate and adaptive immune system pathways to fulfill their antiviral and antitumoral activity. ${ }^{37,38}$

While IFN- $\alpha$ and IFN- $\beta$ is detected by the IFN receptor (IFNAR), IFN- $\lambda$ is recognized by a heterodimer of the IL-10 and IFN- $\lambda$ receptors (IL-10R2 and IFN $\lambda \mathrm{R} 1$, respectively), which is tissue-dependent and expressed primarily in epithelial cells, liver tissue, and peripheral blood mononuclear cells. ${ }^{39}$ However, both receptors trigger the Janus kinasesignal transducer and activator of transcription (JAK-STAT) pathway, activating a set of IFN-stimulated genes (ISGs) engaged in a wide range of antiviral and antiproliferative activities. $^{39-41}$

\section{Hypothetical role of IL28B SNP in response to PEG-IFN- $\alpha /$ RBV treatment}

Evidence regarding the association between ISGs in the liver or peripheral blood mononuclear cells and $I L 28 B$ genotype or response to IFN therapy is widely recognized by numerous studies. However, the biological pathways relating IL28B genetic variants to spontaneous and/or treatment-induced $\mathrm{HCV}$ clearance are still unknown.

When the innate immune system detects the presence of HCV RNA, mitochondrial antiviral-signaling protein stimulates expression and secretion of IFN- $\alpha$, IFN- $\beta$, and IFN- $\lambda$. Cell surface receptors detect IFNs and trigger a signal cascade, stimulating a large number of ISGs that generate intracellular antiviral activity which eliminates viral replication. ${ }^{42-45}$

In individuals with the favorable IL28B allele (rs12979860 CC), low levels of IFN- $\lambda$ and therefore weak $I S G$ expression are observed. Despite the fact that this 
response might be enough to eliminate the virus at low viral loads, the cell is more sensitive to IFN and high viral loads can accumulate in the patient (Figure $1 \mathrm{~A}$ and B). ${ }^{46}$

Constant induction of the IFN signaling pathway in the presence of the virus seems to be a common characteristic in patients with the unfavorable genotypes (rs12979860 CT/TT). In spite of higher baseline $I S G$ expression levels, virus elimination is not possible, due to the fact that IFN-inhibitory molecules (SOCS3 [suppressor of cytokine signaling 3] and PIAS [protein inhibitor of activated STAT]) at the same time activate a negative regulation of the JAK-STAT pathway. Consequently, the cell is less sensitive to IFN, which means that the hepatocyte is not only unable to eliminate the virus but also lacks the ability to stimulate more powerful ISG expression when exogenous IFN- $\alpha$ is provided during treatment (Figure $2 \mathrm{~A}$ and $\mathrm{B}$ ). ${ }^{47}$

When IFN- $\alpha$ therapy is administered, various possibilities might occur depending on the $I L 28 B$ genotype. The development of a more vigorous therapeutic response and successful viral elimination can be detected in patients with the favorable $I L 28 B$ allele (rs12979860 CC), as a consequence of unrestrained IFN signal transduction and strong ISG stimulation (Figure $1 \mathrm{C}$ and D). ${ }^{46}$
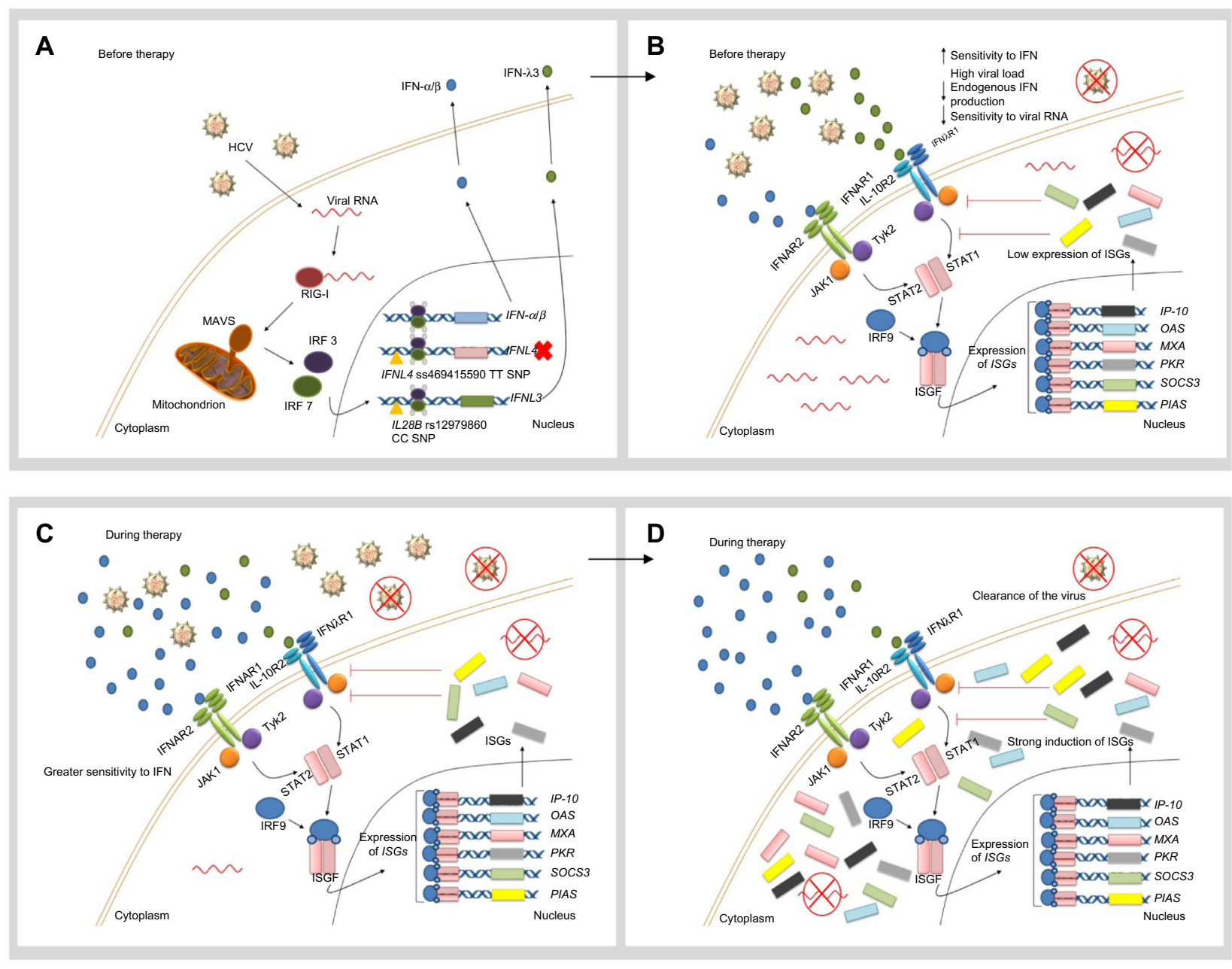

Figure I Hypothetical role of favorable IL28B and IFNL4 genotypes in the response to IFN therapy.

Notes: (A) When the innate immune system, including the RIG-I-IFIHI pathway, detects the presence of HCV RNA, the adaptor protein MAVS stimulates expression and secretion of IFN- $\alpha$, IFN- $\beta$, and IFN- $\lambda$. In individuals with the favorable IFNL4 genotype, the TT allele creates a frame shift in the gene which inactivates protein expression. In individuals with the favorable IL28B genotype (rs I 2979860 CC), HCV RNA seems to induce only weak expression of IFN- $\lambda 3$. (B) IFN- $\alpha$ and IFN- $\beta$ are recognized by IFNAR, whereas IFN- $\lambda$ binds to the ILIOR-IFN $\lambda$ R receptor complex. Both receptors trigger the JAK-STAT pathway, which induces translocation of an ISGF complex to the nucleus, where it binds to the IFN-stimulated response elements of multiple ISGs. In individuals with the rs 12979860 CC genotype, low levels of IFN- $\lambda$ and therefore weak ISG expression are observed. Despite the fact that this response might be enough to clear the virus at low viral loads, high viral loads can accumulate in the patient. (C) During treatment with IFN- $\alpha$, the cell is more sensitive to IFN. (D) Therefore, IFN signal transduction is unrestrained and a strong ISG stimulation is detected. Consequently, a more vigorous therapeutic response is developed and the virus can be successfully eliminated. Reprinted by permission from Macmillan Publishers Ltd: Nature Reviews Gastroenterology and Hepatology, Hayes CN, Imamura M, Aikata H, Chayama K. Genetics of IL28B and HCV - response to infection and treatment. 2012;9(7):406-417, copyright @ 2012.46

Abbreviations: $\mathrm{HCV}$, hepatitis $\mathrm{C}$ virus; IFN, interferon; IFIHI, IFN-induced helicase $C$ domain-containing protein I; IFNAR, IFN- $\alpha / \beta$ receptor I; IFNL4, interferon lambda 4; LIOR, IL-10 receptor; IL28B, interleukin 28B; IFN $\lambda$ R, IFN $\lambda$ receptor; IP-10, IFN- $\gamma$-inducible protein I0; IRF, IFN regulatory factor; ISG, IFN-stimulated gene; ISGF, IFNstimulated gene factor; JAK, Janus kinase; MAVS, mitochondrial antiviral-signaling protein; MXA, myxovirus resistance protein I (also known as MXI); OAS, 2'5'-oligoadenylate synthase; PIAS, protein inhibitor of activated STAT; PKR, protein kinase RNA-activated (also known as EIF2AK2); RIG-I, retinoic-acid inducible protein I; SNP, single-nucleotide polymorphism; SOCS3, suppressor of cytokine signaling 3; STAT, signal transducer and activator of transcription; Tyk2, tyrosine kinase 2. 

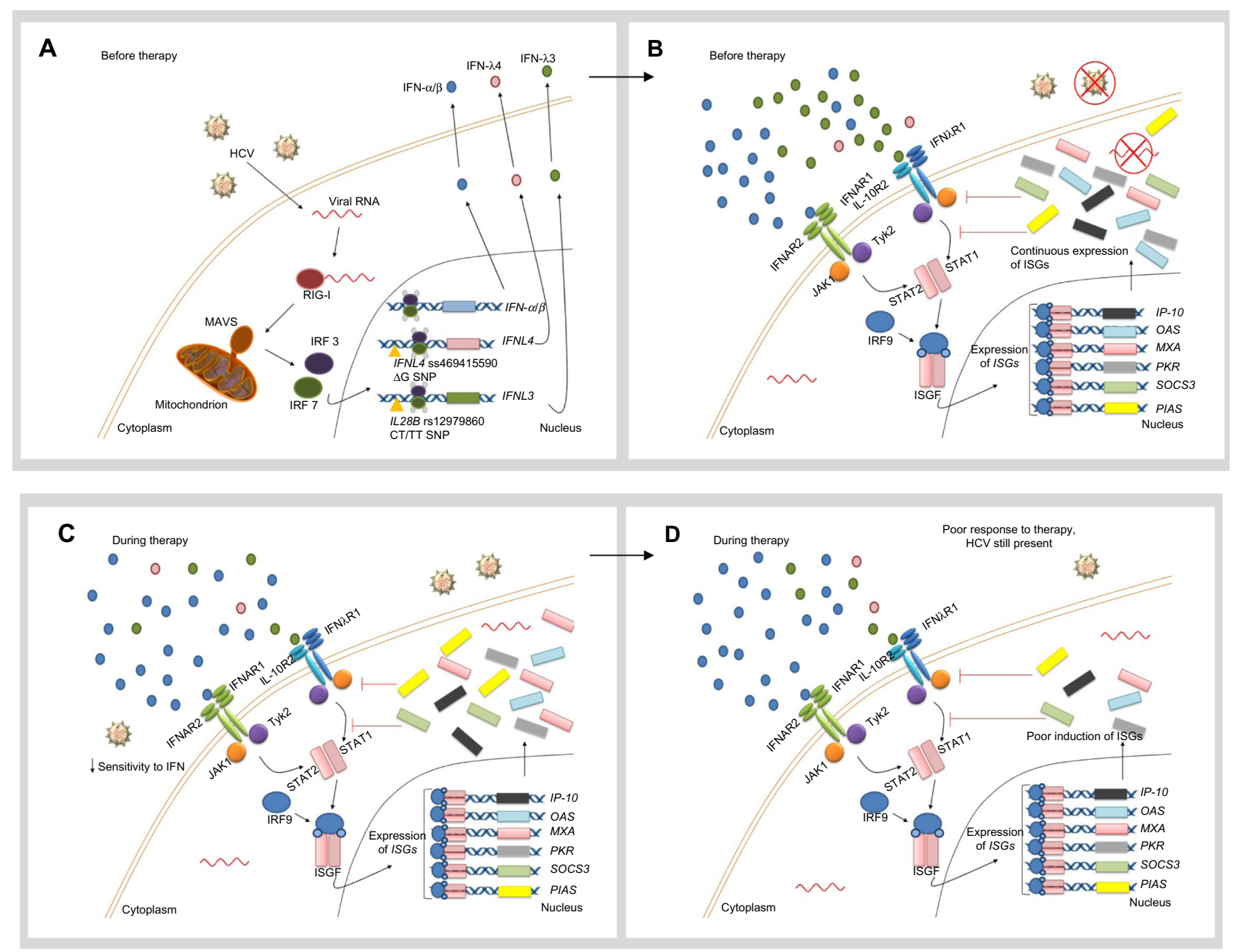

Figure 2 Hypothetical role of unfavorable IL28B and IFNL4 genotypes in the response to IFN therapy.

Notes: (A) When the innate immune system, including the RIG-IIFIHI pathway, detects the presence of HCV RNA, the adaptor protein MAVS stimulates the expression and secretion of IFN- $\alpha$, IFN- $\beta$, and IFN- $\lambda$. In patients with the unfavorable IFNL4 genotype ( $\Delta \mathrm{G}$ allele), the full-length protein is expressed and poorly secreted. On the other hand, constant induction of the IFN signaling pathway in the presence of the virus seems to be a common characteristic in patients with the unfavorable IL28B genotypes (rs I 2979860 CT/TT). (B) IFN- $\alpha$ and IFN- $\beta$ are recognized by IFNAR, whereas IFN- $\lambda$ binds to the ILIOR-I IFN $\lambda$ R receptor complex. Both receptors trigger the JAK-STAT pathway, which induces translocation of an ISGF complex to the nucleus, where it binds to the IFN-stimulated response elements of multiple ISGs. The mechanism by which IFN- $\lambda 4$ impairs HCV clearance remains unclear. In spite of higher baseline ISG expression levels, viral elimination is not possible in patients with the rs I2979860 CT/TT genotypes, due to the fact that negative regulation of the JAK-STAT pathway is being activated at the same time through IFN-inhibitory molecules (SOCS3 and PIAS). (C) When IFN- $\alpha$ is administered as part of therapy in patients with unfavorable IL28B genotypes, the cell shows a low sensitivity to IFN. (D) Exogenous IFN- $\alpha$ is not able to stimulate ISG expression strongly enough to clear the virus. Therefore, the patient exhibits a poor therapeutic response. Reprinted by permission from Macmillan Publishers Ltd: Nature Reviews Gastroenterology and Hepatology, Hayes CN, Imamura M, Aikata H, Chayama K. Genetics of IL28B and HCV - response to infection and treatment. 2012;9(7):406-417, copyright @ 2012.46 Abbreviations: $\mathrm{HCV}$, hepatitis $\mathrm{C}$ virus; IFIHI, IFN-induced helicase $C$ domain-containing protein I; IFNAR, IFN- $\alpha / \beta$ receptor I; IFNL4, interferon lambda 4; ILIOR, IL-I0 receptor; IL28B, interleukin 28B; IFN $\lambda$ R, IFN $\lambda$ receptor; IP-10, IFN- $\gamma$-inducible protein I0; IRF, IFN regulatory factor; ISG, IFN-stimulated gene; ISGF, IFN-stimulated gene factor; JAK, Janus kinase; MAVS, mitochondrial antiviral signaling protein; MXA, myxovirus resistance protein I (also known as MXI); OAS, 2'5'-oligoadenylate synthase; PIAS, protein inhibitor of activated STAT; PKR, protein kinase RNA-activated (also known as EIF2AK2); RIG-I, retinoic-acid inducible protein I; SNP, single-nucleotide polymorphism; SOCS3, suppressor of cytokine signaling 3; STAT, signal transducer and activator of transcription; Tyk2, tyrosine kinase 2.

Conversely, exogenous IFN- $\alpha$ is not able to stimulate $I S G$ expression strongly enough to clear the virus in individuals with unfavorable genotypes (rs12979860 CT/TT). Therefore, the patient exhibits a poor therapeutic response (Figure $2 \mathrm{C}$ and D). ${ }^{46}$

Extensive studies of the genetic region around the IFNL3 gene have recently revealed the existence of a novel gene, ie, the IFNL4 gene, which shows a dinucleotide variant (rs368234815 or ss469415590 TT/ $\Delta \mathrm{G}$ ) in linkage disequilibrium with rs $12979860 .{ }^{48}$ Interestingly, the full-length protein is only expressed in patients with the $\Delta \mathrm{G}$ allele, whereas the TT allele creates a frame shift in the gene that inactivates protein expression (Figures $1 \mathrm{~A}$ and $2 \mathrm{~A}$ ). ${ }^{48}$ In humans, the TT allele is strongly and positively associated with spontaneous or treatment-induced HCV clearance. Thus, in the context of HCV infection, disruption of the IFNL4 gene is beneficial for humans, although the reason for this remains unclear. ${ }^{48,49}$

Like the other three members of the IFN- $\lambda$ family, this new type III IFN binds to the same heterodimeric receptor and activates the JAK-STAT pathway. Moreover, it exhibits 
strong antiviral activity in vitro. However, unlike the majority of IFNs, IFN- $\lambda 4$ protein is poorly secreted (Figure $2 \mathrm{~A}$ ), and it is hypothesized that it might block IL-10R2/IFN $\lambda$ R1 receptor binding for the remaining IFN- $\lambda s$, thus impairing HCV clearance. ${ }^{36}$

Moreover, it was determined that, in peripheral blood mononuclear cells, ss469415590 (but not rs12979860) is responsible for the stimulation of $I L 28 B$ and IFN- $\gamma$-inducible protein 10 messenger RNA, high plasma levels of which have been also shown to be related to a poor therapeutic response in chronically infected HCV patients. ${ }^{49}$ These observations offer a new understanding into the genetic mechanism of $\mathrm{HCV}$ clearance and have a strong and direct impact on the clinical management of $\mathrm{HCV}$ infection.

\section{Other host genetic polymorphisms in the HCV treatment response}

Although the influence of $I L 28 B$ on HCV infection and treatment have been reviewed by numerous studies since publication of the landmark papers, it has been shown that SNPs at other genes could also be involved in HCV treatment susceptibility and the risk of drug-related toxicities. ${ }^{50}$

\section{Inosine triphosphatase}

PEG-IFN- $\alpha / R B V$ therapy is associated with several treatmentlimiting adverse effects. One of the most important is RBVinduced hemolytic anemia, which motivates withdrawal of $\mathrm{HCV}$ therapy in about $15 \%$ of patients. ${ }^{51}$ In a recent genomewide association study, it was concluded that the reduction in hemoglobin detected after 4 weeks of treatment is significantly associated with the genotypes of SNP rs6051702. The gene locus responsible for RBV-induced hemolytic anemia is in the inosine triphosphatase gene on chromosome 20, which encodes inosine triphosphate pyrophosphohydrolase, a protein that hydrolyses inosine triphosphate to its monophosphate derivative. ${ }^{52}$ Two functional variants are involved in the reported association, ie, a missense variant in exon 2 (rs1127354) and a splice-altering SNP in intron 2 (rs7270101), which lead to inosine triphosphate pyrophosphohydrolase deficiency, a benign red cell enzymopathy characterized by accumulation of inosine triphosphate in erythrocytes and related to a protective effect against $\mathrm{RBV}$-induced hemolytic anemia in HCV genotype 1-infected patients receiving PEGIFN- $\alpha /$ RBV or telaprevir-based triple therapy. ${ }^{53-56}$

It is important to note that although related to a decreased risk of hemolytic anemia, patients carrying polymorphisms encoding reduced predicted inosine triphosphate pyrophosphohydrolase activity are more prone to develop thrombocytopenia. ${ }^{57}$ Moreover, recent reports show that, in addition to a better prediction of anemia, RBV dose reduction, and need for erythropoietin, inosine triphosphatase deficiency is also associated with SVR in patients infected with HCV genotypes $1 / 4$ or $2 / 3.58,59$

\section{Low-density lipoprotein cholesterol receptor gene}

A higher plasma low-density lipoprotein (LDL) cholesterol level is an independent predictor of an SVR to PEG-IFN- $\alpha /$ RBV, and a genetic variant of the LDL cholesterol receptor gene $(L D L R)$, an SNP located in the $3^{\prime}$ UTR region of the $L D L R$ gene, has been shown to predict an SVR to PEG-IFN- $\alpha /$ RBV therapy in chronic $\mathrm{HCV}$, as well as in patients coinfected with human immunodeficiency virus/HCV. ${ }^{60,61}$ Moreover, the $L D L R$ and $I L 28 B$ genotypes seem to have a synergistic effect on SVR. ${ }^{62}$ Given that $L D L R$ is one of the putative HCV receptors, both $I L 28 B$ and $L D L R$ genotypes could interact to regulate the life cycle of $\mathrm{HCV}^{62,63}$ For this reason, combined use of both $L D L R$ and $I L 28 B$ genotypes is more potent in improving the prediction of SVR than separate analysis of these allelic variants.

\section{Vitamin D receptor}

Although $I L 28 B$ variants are the strongest predictors of the response to PEG-IFN- $\alpha / R B V$, recent data suggest that vitamin D may also be an important determinant of response to treatment. ${ }^{60} \mathrm{~A}$ correlation between $25-\mathrm{OH}$ vitamin $\mathrm{D}$ deficiency and non-response to PEG-IFN- $\alpha /$ RBV therapy has been observed. ${ }^{64}$ Therefore, genetic variations of the vitamin $\mathrm{D}$ receptor offer a possibility to analyze further the effects of vitamin D on the outcome of HCV therapy. ${ }^{65,66}$

\section{Impact of HCV pharmacogenomics on patient-focused perspectives}

When compared with the general population or patients with chronic hepatitis B, patients with chronic HCV infection usually have lower health-related quality of life. ${ }^{67}$ In particular, injecting drug users infected with HCV appear to have a lower health-related quality of life when compared with patients infected via blood transfusions. ${ }^{67,68}$

It has been reported that $\mathrm{HCV}$ infection rates are at least five times higher among patients with severe mental illness and that the prevalence of psychiatric and substance use disorders is more frequent among HCV-infected patients when compared with the general population. In fact, this correlation represents an obstacle to the therapeutic and clinical management of this infection. ${ }^{69}$ Interestingly, other studies have indicated that another factor related to reduced health-related quality of life is awareness of the $\mathrm{HCV}$ infection per se. ${ }^{68}$ 
While successful PEG-IFN- $\alpha /$ RBV treatment appears to ameliorate health-related quality of life, it is usually affected and declines during the therapeutic course as a consequence of severe side effects, such as RBV-induced hemolytic anemia. ${ }^{70,71}$ Moreover, a significant increase in psychiatric and substance abuse disorders during HCV antiviral treatment regimens has been reported, even in patients with no prior history. ${ }^{72}$ As a result, HCV patients suffering from psychiatric disorders are less likely to be eligible for therapeutic schemes, thus increasing the morbidity and mortality rates in these individuals. ${ }^{73}$

Interestingly, a recent Japanese study was the first to confirm that low health-related quality of life before treatment is significantly associated with SVR to PEG-IFN- $\alpha /$ RBV therapy. ${ }^{74}$ Chronic HCV infection not only decreases quality of life in patients with the disease, but also represents a major public health burden.

As mentioned earlier, IL28B genotype testing could be useful to detect those patients who are less likely to adhere to treatment or to respond to it; therefore, it could be part of a cost-effective strategy that also improves individual outcomes and quality of life, as it would be able to decrease treatmentassociated morbidity and costs. ${ }^{75}$ For example, offering patients with favorable $I L 28 B$ genotypes a shorter, lower-cost regimen with PEG-IFN- $\alpha / R B V$, followed by direct-acting antiviral agents for those with unfavorable variants or those who relapse, could be more cost-effective than treating all patients initially with regimens that include direct-acting antiviral agents. ${ }^{75,76}$

In addition, since antiviral treatment is lengthy and often complicated, IL28B prediction may encourage patients with favorable genotypes to start therapy or to continue with their personalized treatment regimens. The number of therapeutic possibilities will increase in the near future, but $I L 28 B$ genotyping will still be useful for optimization of treatment algorithms.

\section{Conclusion}

Knowledge related to host genetic factors represents a milestone in the treatment of HCV from a clinical and research point of view. In the coming years, the development of new and effective drugs included in quadruple or IFN-free regimens might eclipse the influence of $I L 28 B$. However, its genotyping will still be a useful tool to predict treatment outcome and may help to make decisions regarding adequate treatment schemes, especially for prior non-responding patients.

Moving forward, the major challenge will lie in effective interpretation of this new knowledge in clinical practice, which will need the commitment of patients, clinicians, researchers, health administrators, and the pharmaceutical industry. The main goal will be an ideal treatment for chronic $\mathrm{HCV}$ infection, which must be efficacious, simple, safe, and well tolerated, and also of short duration and cost-effective. The aim of personalized health care may now be one step closer for HCV-infected patients.

\section{Acknowledgments}

This work is supported by grants from the Instituto de Ciencias Básicas y Medicina Experimental, the La Fundación para el Desarrollo de las Ciencias Básicas, and the Italian Hospital of Buenos Aires Research Bureau.

\section{Disclosure}

The authors report no conflicts of interest in this work.

\section{References}

1. Wang L, McLeod HL, Weinshilboum RL. Genomics and drug response. N Engl J Med. 2011;364(12):1144-1153.

2. Weinshilboum RM, Wang L. Pharmacogenetics and pharmacogenomics: development, science and translation. Annu Rev Genomics Hum Genet. 2006; 7:223-245.

3. International HapMap Consortium. A haplotype map of the human genome. Nature. 2005;437(7063):1299-1320.

4. Thursz M, Yee L, Khakoo S. Understanding the host genetics of chronic hepatitis B and C. Semin Liver Dis. 2011;31(2):115-127.

5. Suppiah V, Moldovan M, Ahlenstiel G, et al. Interleukin 28B is associated with response to hepatitis $\mathrm{C}$ interferon-alpha and ribavirin therapy. Nat Genet. 2009;41(10):1100-1104.

6. Tanaka Y, Nishida N, Sugiyama M, et al. Genome-wide association of interleukin $28 \mathrm{~B}$ with response to interferon alpha and ribavirin therapy for chronic hepatitis C. Nat Genet. 2009;41(10):1105-1109.

7. Ge D, Fellay J, Thompson AJ, et al. Genetic variation in interleukin 28B predicts hepatitis C treatment-induced viral clearance. Nature. 2009; 461(7262):399-401.

8. Rauch A, Kutalik Z, Descombes P; for Swiss Hepatitis C Cohort Study and Swiss HIV Cohort Study. Genetic variation in interleukin 28B is associated with chronic hepatitis $\mathrm{C}$ and treatment failure: genome-wide association study. Gastroenterology. 2010;138(4):1338-1345.

9. Thomas DL, Thio CL, Martin MP, et al. Genetic variation in IL28B and spontaneous clearance of hepatitis C virus. Nature. 2009; 461(7265):798-801.

10. Redal M, Belloso WH, Garfi I, Scibona P, Isolabella S. Pharmacogenomics in gastroenterology. In: Sanoudou D, editor. Clinical Applications of Pharmacogenetics. Rijeka, Croatia: In Tech; 2012.

11. Belloso WH, Redal MA. Pharmacogenomics and the path towards personalized medicine. Medicina (B Aires). 2010;70(3):265-274.

12. Choo QL, Kuo G, Weiner AJ, Overby LR, Bradley DW, Houghton M. Isolation of a cDNA clone derived from a blood-borne non-A, non-B viral hepatitis genome. Science. 1989;244(4902):359-362.

13. Mühlberger N, Schwarzer R, Lettmeier B, Sroczynski G, Zeuzem S, Siebert U. HCV-related burden of disease in Europe: a systematic assessment of incidence, prevalence, morbidity, and mortality. BMC Public Health. 2009;9:34.

14. Hadziyannis SJ, Sette H Jr, Morgan TR; for PEGASYS International Study Group. Peginterferon-alpha2a and ribavirin combination therapy in chronic hepatitis $\mathrm{C}$ : a randomized study of treatment duration and ribavirin dose. Ann Intern Med. 2004;140(5):346-355.

15. Fowell AJ, Nash KL. Telaprevir: a new hope in the treatment of chronic hepatitis C? Adv Ther. 2010;27(8):512-522.

16. Thomas DL, Astemborski J, Rai RM, et al. The natural history of hepatitis $\mathrm{C}$ virus infection: host, viral, and environmental factors. JAMA. 2000;284(4):450-456. 
17. Aborsangaya KB, Dembinski I, Khatkar S, Alphonse MP, Nickerson P, Rempel JD. Impact of aboriginal ethnicity on HCV core-induced IL-10 synthesis: interaction with IL-10 gene polymorphisms. Hepatology. 2007;45(3):623-630.

18. Trinks J, Hulaniuk ML, Caputo M, et al. Distribution of genetic polymorphisms associated to hepatitis $\mathrm{C}$ virus $(\mathrm{HCV})$ antiviral response in a multiethnic and admixed population. Pharmacogenomics J. May 20, 2014. [Epub ahead of print.]

19. Mangia A, Thompson AJ, Santoro R, et al. An IL28B polymorphism determines treatment response of hepatitis $C$ virus genotype 2 or 3 patients who do not achieve a rapid virologic response. Gastroenterology. 2010; 139(3):821-827.

20. Sarrazin C, Susser S, Doehring A, et al. Importance of IL28B gene polymorphisms in hepatitis $\mathrm{C}$ virus genotype 2 and 3 infected patients. $J$ Hepatol. 2011;54(3):415-421.

21. Scherzer TM, Stättermayer AF, Strasser M, et al. Impact of IL28B on treatment outcome in hepatitis $\mathrm{C}$ virus $\mathrm{G} 1 / 4$ patients receiving response-guided therapy with peginterferon alpha-2a (40KD)/ribavirin. Hepatology. 2011;54(5):1518-1526.

22. Montes-Cano MA, García-Lozano JR, Abad-Molina C, et al. Interleukin-28B genetic variants and hepatitis virus infection by different viral genotypes. Hepatology. 2010;52(1):33-37.

23. Rallon NI, Naggie S, Benito JM, et al. Association of a single nucleotide polymorphism near the interleukin-28B gene with response to hepatitis $\mathrm{C}$ therapy in $\mathrm{HIV} /$ hepatitis $\mathrm{C}$ virus-coinfected patients. AIDS. 2010;24(8):F23-F29.

24. Yu ML, Huang CF, Huang JF, et al. Role of interleukin-28B polymorphisms in the treatment of hepatitis $\mathrm{C}$ virus genotype 2 infection in Asian patients. Hepatology. 2011;53(1):7-13.

25. Mangia A, Thompson AJ, Santoro R, et al. Limited use of interleukin 28B in the setting of response-guided treatment with detailed on-treatment virological monitoring. Hepatology. 2011;54(3):772-780.

26. Thompson AJ, Muir AJ, Sulkowski MS, et al. Interleukin-28B polymorphism improves viral kinetics and is the strongest pretreatment predictor of sustained virologic response in genotype 1 hepatitis C virus. Gastroenterology. 2010;139(1):120-129.

27. Chayama K, Tsubota A, Kobayashi M, et al. Pretreatment virus load and multiple amino acid substitutions in the interferon sensitivity-determining region predict the outcome of interferon treatment in patients with chronic genotype $1 \mathrm{~b}$ hepatitis $\mathrm{C}$ virus infection. Hepatology. 1997;25(3):745-749.

28. Hayes CN, Kobayashi M, Akuta N, et al. HCV substitutions and IL28B polymorphisms on outcome of peg-interferon plus ribavirin combination therapy. Gut. 2011;60(2):261-267.

29. Lindh M, Lagging M, Arnholm B, et al. IL28B polymorphisms determine early viral kinetics and treatment outcome in patients receiving peginterferon/ribavirin for chronic hepatitis $\mathrm{C}$ genotype 1. JViral Hepat. 2011;18(7):e325-e331.

30. Ochi H, Maekawa T, Abe H, et al. IL-28B predicts response to chronic hepatitis $\mathrm{C}$ therapy - fine-mapping and replication study in Asian populations. J Gen Virol. 2011;92 Pt 5:1071-1081.

31. Stättermayer AF, Stauber R, Hofer H, et al. Impact of IL28B genotype on the early and sustained virologic response in treatmentnaive patients with chronic hepatitis C. Clin Gastroenterol Hepatol. 2011;9(4):344-350.

32. Lin CY, Chen JY, Lin TN, et al. IL28B SNP rs12979860 is a critical predictor for on-treatment and sustained virologic response in patients with hepatitis C virus genotype-1 infection. PLoS One. 2011;6(3):e18322.

33. Fukuhara T, Taketomi A, Motomura T, et al. Variants in IL28B in liver recipients and donors correlate with response to peg-interferon and ribavirin therapy for recurrent hepatitis C. Gastroenterology. 2010;139(5):1577-1585.

34. Charlton MR, Thompson A, Veldt BJ, et al. Interleukin-28B polymorphisms are associated with histological recurrence and treatment response following liver transplantation in patients with hepatitis $\mathrm{C}$ virus infection. Hepatology. 2011;53(1):317-324.
35. Coto-Llerena M, Pérez-del-Pulgar S, Crespo G, et al. Donor and recipient IL28B polymorphisms in HCV-infected patients undergoing antiviral therapy before and after liver transplantation. Am J Transplant. 2011;11(5):1051-1057.

36. O'Brien TR, Prokunina-Olsson L, Donnelly RP. IFN- $\lambda 4$ : the paradoxical new member of the interferon lambda family. J Interferon Cytokine Res. April 30, 2014. [Epub ahead of print.]

37. Yoshimoto K, Kishida T, Nakano H, et al. Interleukin-28B acts synergistically with cisplatin to suppress the growth of head and neck squamous cell carcinoma. J Immunother. 2011;34(2):139-148.

38. Morrow MP, Yan J, Pankhong P, et al. IL-28B/IFN-lambda 3 drives granzyme B loading and significantly increases CTL killing activity in macaques. Mol Ther. 2010:18(9):1714-1723.

39. Kotenko SV, Gallagher G, Baurin VV, et al. IFN-lambdas mediate antiviral protection through a distinct class II cytokine receptor complex. Nat Immunol. 2003;4(1):69-77.

40. Zhang L, Jilg N, Shao RX, et al. IL28B inhibits hepatitis C virus replication through the JAK-STAT pathway. J Hepatol. 2011;55(2):289-298.

41. Zhou Z, Hamming OJ, Ank N, Paludan SR, Nielsen AL, Hartmann R. Type III interferon (IFN) induces a type I IFN-like response in a restricted subset of cells through signaling pathways involving both the Jak-STAT pathway and the mitogen-activated protein kinases. J Virol. 2007;81(14):7749-7758.

42. Rehermann B. Hepatitis $C$ virus versus innate and adaptive immune responses: a tale of coevolution and coexistence. J Clin Invest. 2009; 119(7):1745-1754.

43. Kawai T, Takahashi K, Sato S, et al. IPS-1, an adaptor triggering RIG-I- and Mda5-mediated type I interferon induction. Nat Immunol. 2005;6(10):981-988.

44. Xu LG, Wang YY, Han KJ, Li LY, Zhai Z, Shu HB. VISA is an adapter protein required for virus-triggered IFN-beta signaling. Mol Cell. 2005;19(6):727-740.

45. Seth RB, Sun L, Ea CK, Chen ZJ. Identification and characterization of MAVS, a mitochondrial antiviral signaling protein that activates NF-kappaB and IRF 3. Cell. 2005;122(5):669-682.

46. Hayes CN, Imamura M, Aikata H, Chayama K. Genetics of IL28B and $\mathrm{HCV}$ - response to infection and treatment. Nat Rev Gastroenterol Hepatol. 2012;9(7):406-417.

47. Asahina Y, Tsuchiya K, Muraoka M, et al. Association of gene expression involving innate immunity and genetic variation in IL28B with antiviral response. Hepatology. 2012;55(1):20-29.

48. Prokunina-Olsson L, Muchmore B, Tang W, et al. A variant upstream of IFNL3 (IL28B) creating a new interferon gene IFNL4 is associated with impaired clearance of hepatitis C virus. Nat Genet. 2013;45(2): 164-171.

49. Bibert S, Roger T, Calandra T, et al. IL28B expression depends on a novel TT/-G polymorphism which improves HCV clearance prediction. J Exp Med. 2013;210(6):1109-1116.

50. Soriano V, Poveda E, Vispo E, Labarga P, Rallón N, Barreiro P. Pharmacogenetics of hepatitis C. J Antimicrob Chemother. 2012;67(3): 523-529.

51. De Franceschi L, Fattovich G, Turrini, et al. Hemolytic anemia induced by ribavirin therapy in patients with chronic hepatitis $\mathrm{C}$ virus infection: role of membrane oxidative damage. Hepatology. 2000;31(4):997-1004.

52. Fellay J, Thompson AJ, Ge D, et al. ITPA gene variants protect against anemia in patients treated for chronic hepatitis C. Nature. 2010;464(7287):405-408

53. Bierau J, Lindhout M, Bakker JA. Pharmacogenetic significance of inosine triphosphatase. Pharmacogenomics. 2007;8(9):1221-1228.

54. Stocco G, Cheok MH, Crews KR, et al. Genetic polymorphism of inosine triphosphate pyrophosphatase is a determinant of mercaptopurine metabolism and toxicity during treatment for acute lymphoblastic leukemia. Clin Pharmacol Ther. 2009;85(2):164-172.

55. Thompson A, Fellay J, Patel K, et al. Variants in the ITPA gene protect against ribavirin-induced hemolytic anemia and decrease the need for ribavirin dose reduction. Gastroenterology. 2010;139(4):1181-1189. 
56. Ogawa E, Furusyo N, Nakamuta M, et al. Clinical milestones for the prediction of severe anemia by chronic hepatitis $\mathrm{C}$ patients receiving telaprevir-based triple therapy. J Hepatol. 2013;59(4):667-674.

57. Thompson AJ, Clark PJ, Singh A, et al. Genome-wide association study of interferon-related cytopenia in chronic hepatitis C patients. J Hepatol. 2012;56(2):313-319.

58. Clark PJ, Aghemo A, Degasperi E, et al. Inosine triphosphatase deficiency helps predict anaemia, anaemia management and response in chronic hepatitis C therapy. J Viral Hepat. 2013;20(12):858-866.

59. Rembeck K, Waldenström J, Hellstrand K, et al. Variants of the inosine triphosphate pyrophosphatase gene are associated with reduced relapse risk following treatment for $\mathrm{HCV}$ genotype 2/3. Hepatology. 2014;59(6):2131-2139.

60. Afdhal N, McHutchison J, Zeuzem S, et al. Hepatitis C pharmacogenetics: state of the art in 2010. Hepatology. 2011;53(1):336-345.

61. Hening BJ, Hellier S, Frodsham AJ, et al. Association of low-density lipoprotein receptor polymorphisms and outcome of hepatitis C infection. Genes Immun. 2002;3(6):359-367.

62. Pineda JA, Caruz A, Di Lello FA, et al. Low-density lipoprotein receptor genotyping enhances the predictive value of IL28B genotype in HIV/ hepatitis C virus-coinfected patients. AIDS. 2011;25(11): 1415-1420.

63. Pineda JA, Caruz A, Rivero A, et al. Prediction of response to pegylated interferon plus ribavirin by IL28B gene variation in patients coinfected with HIV and hepatitis C virus. Clin Infect Dis. 2010;51(7):788-795.

64. Petta $\mathrm{S}$, Cammà $\mathrm{C}, \mathrm{Scazzone} \mathrm{C}$, et al. Low vitamin $\mathrm{D}$ serum level is related to severe fibrosis and low responsiveness to interferon-based therapy in genotype 1 chronic hepatitis C. Hepatology. 2010;51(4): 1158-1167.

65. Lange CM, Bojunga J, Ramos-Lopez E, et al. Vitamin D deficiency and a CYP27B1-1260 promoter polymorphism are associated with chronic hepatitis $\mathrm{C}$ and poor response to interferon-alfa based therapy. J Hepatol. 2011;54(5):887-893.

66. Uitterlinden AG, Fang Y, Van Meurs JB, Pols HA, Van Leeuwen JP. Genetics and biology of vitamin D receptor polymorphisms. Gene. 2004;338(2):143-156
67. Foster GR, Goldin RD, Thomas HC. Chronic hepatitis C virus infection causes a significant reduction in quality of life in the absence of cirrhosis. Hepatology. 1998;27(1):209-212.

68. Dalgard O, Egeland A, Skaug K, Vilimas K, Steen T. Health-related quality of life in active injecting drug users with and without chronic hepatitis C virus infection. Hepatology. 2004;39(1):74-80.

69. Rifai MA, Gleason OC, Sabouni D. Psychiatric care of the patient with hepatitis C: a review of the literature. Prim Care Companion J Clin Psychiatry. 2010;12(6):PCC.09r00877.

70. McHutchison JG, Ware JE Jr, Bayliss MS; for Hepatitis Interventional Therapy Group. The effects of interferon alpha-2b in combination with ribavirin on health related quality of life and work productivity. J Hepatol. 2001;34(1):140-147.

71. Ware JE Jr, Bayliss MS, Mannocchia M, Davis GL. Health-related quality of life in chronic hepatitis C: impact of disease and treatment response. The Interventional Therapy Group. Hepatology. 1999;30(2): $550-555$.

72. Bernstein D, Kleinman L, Barker CM, Revicki DA, Green J. Relationship of health-related quality of life to treatment adherence and sustained response in chronic hepatitis $\mathrm{C}$ patients. Hepatology. 2002;35(3):704-708.

73. Rifai MA, Moles JK, Short DD. Hepatitis C treatment eligibility and outcomes among patients with psychiatric illness. Psychiatr Serv. 2006;57(4):570-572.

74. Matsushita H, Ikeda F, Iwasaki Y, et al. Assessment of health-related quality of life and how it predicts the outcome of pegylated interferon and ribavirin therapy for chronic hepatitis C. J Gastroenterol Hepatol. 2014;29(2):337-343.

75. Liu S, Cipriano LE, Holodniy M, Owens DK, Goldhaber-Fiebert JD New protease inhibitors for the treatment of chronic hepatitis C: a costeffectiveness analysis. Ann Intern Med. 2012;156(4):279-290.

76. Thompson AJ, McHutchison JG. Will IL28B polymorphism remain relevant in the era of direct-acting antiviral agents for hepatitis $\mathrm{C}$ virus? Hepatology. 2012;56(1):373-381
Pharmacogenomics and Personalized Medicine

\section{Publish your work in this journal}

Pharmacogenomics and Personalized Medicine is an international, peerreviewed, open access journal characterizing the influence of genotype on pharmacology leading to the development of personalized treatment programs and individualized drug selection for improved safety, efficacy and sustainability. This journal is indexed on the American Chemical

\section{Dovepress}

Society's Chemical Abstracts Service (CAS). The manuscript management system is completely online and includes a very quick and fair peer-review system, which is all easy to use. Visit http://www.dovepress. $\mathrm{com} /$ testimonials.php to read real quotes from published authors. 